Activity and Related Interplanetary and Terrestrial Phenomena; Springer: New York; 1973) with those of E.S. Gerety et al. (J. atmos. Sci., 34, 673; 1977) and M. Dehsara and K. Cheak (Arch. Met. Geoph. Biokl., Ser. B, 18, 253; 1970). But they seek to explain these, not by a critical examination of the conclusions of, methodology, and data sets used by Xanthakis, but by appealing to a more complex hypothesis allowing more degrees of freedom. Thus on page 130 they say "If the pattern of the global distribution of excess rainfall .... undergoes secular changes due to long-term variations in extraterrestrial or even terrestrial influences, averages over wide geographic expanses could very well exhibit correlation reversals with sunspot number ... Analysis along (these) lines might reconcile some of the discrepancies ...".

This is a common argument used by the protagonists of solar effects but in the absence of specific theories as to how things ought to change in time or space it simply allows infinite room to manoeuvre, 'explaining' all inconsistencies and proving nothing. It is to the authors' credit that they make this argument fairly explicit in a section headed "Correlation Reversals and Failures", but it is nevertheless a dangerous argument since it removes the incentive towards a truly critical examination of the claims in the literature. As if to prove my point, subsequent admissions by J. Xanthakis (Nature, 280, $254 ; 1979)$ that he in fact selected his data $a$ posteriori have now clearly invalidated the significance of his claimed results.

Similar criticisms can be made of the authors' rather uncritical acceptance of many other contradictory claims in the literature, for example in their discussions of much of King's work, including King's treatment of rainfall at Fortaleza (pages 119-120) and of Bowen's claims for Australian rainfall (pages 88 et seq).

So far my comments have been rather negative. However I want to pay tribute to Herman and Goldberg for several important things. One is the comprehensive (if not complete) nature of their survey and its clear presentation. In particular the excellent indexing greatly enhances the value of the book. Their highlighting of some of the important inconsistencies and breakdowns in the reported correlations is another big plus.

Perhaps the greatest virtue of the book is its emphasis on the need to develop and test physical theories without which the study of solar-weather/climate relationships will never emerge from its present morass. This emphasis will be found in the authors' very first sentence (Preface, page v) and is substantiated in a chapter devoted to possible "Physical Processes and Mechanisms" (chapter 6) and in the final chapter "Guidelines for Experiments"' (chapter 8). Inevitably, coming from people deeply involved in research in relevant areas, this emphasis seems to be rather self-serving.
Nevertheless it is a necessary and correct general emphasis, whatever we may think of their particular suggestions and their too ready acceptance of apparently relevant but dubious claims in the literature.

In summary then, I find Herman and Goldberg's book to be comprehensive (although not perfectly so) but regrettably uncritical in its approach to the literature. It has a desirable emphasis on the need for physical theories and explanations, and on attempting to isolate critical experiments. It also draws together information concerning a wide range of possibly relevant phenomena and processes. Although the case for rejecting the null hypothesis that there are no significant effects has not been proven by this book,

\section{Kinetoplastid biology}

\section{J.R. Baker}

Biology of the Kinetoplastida. Vol. 2. Edited by W.H.R. Lumsden and D.A. Evans. Pp.738. (Academic: London, New York and San Francisco, 1979.) £45; \$94.

VoLUME 1 of this two-part work is an invaluable reference on trypanosomes and leishmanias, serving as an 'in-filler' of gaps in other standard works as well as presenting new developments in betterknown fields. The present volume seems certain to follow suit. Its net is cast wider than its predecessor's, but the emphasis of its fifteen chapters is on parasites of man and domestic animals.

J.J. Shaw and R. Lainson review the ever-changing scene of leishmanial taxonomy and epidemiology and introduce three subgeneric "sections". R. KillickKendrick fully discusses Leishmania in its vector; and V.P. Sergiev describes the epidemiology of leishmaniasis, now mainly zoonotic, in USSR. M.A. Miles discusses biochemical and immunological heterogeneity of Trypanosoma cruzi and the problems arising therefrom; and its pathogenesis and biochemistry are

- The second edition of The Dynamics of the Upper Ocean, by O.M. Phillips (for review, see Nature, 272, 194; 1978), has been published by Cambridge University Press in paperback at $£ 7.95$.

- In the review of Image Analysis, Enhancement and Interpretation, by D.L. Missell (Nature, 282, 885; 1979), the prices were incorrectly quoted, thus making the final criticisms of the reviewer unfounded. These should have read: Hardback \$60, Dfl.135; paperback \$31.75, Dfl.65.

-In the review of Scientific Models and Man (Nature, 283, 113; 1979), the name of one of the lecturers was incorrectly quoted. This should have been: Donald Michie. there nevertheless remains a case for supporting further research directed with physical insight at the hypothesis that there just might be significant effects. We might at least usefully attempt to see how far down such effects penetrate into the atmosphere and to set upper limits on their magnitude in the troposphere. Read with healthy skepticism and critical discernment, Herman and Goldberg's book makes a useful contribution to such an effort.

A.B. Pittock is a Principal Research Scientist with the CSIRO Division of Atmospheric Physics, Mordialloc, Australia.

reviewed respectively by W.L. Tafuri and by W.E. Gutteridge and G.W. Rogerson. W.E. Ormerod considers old and new concepts of the life cycle of $T$. brucei in mammals and heretically suggests that it is not the "stumpy" form which infects tsetse, and that a special "tissue phase"' exists. W.J. Herbert and D. Parratt stimulatingly discuss virulence ("the capacity ... to damage... its host") and heterophile antibodies in (almost exclusively African) trypanosomiasis, speculating on their significance.

Other chapters deal with kinetoplastids of arthropods (F.G. Wallace), lizards (V.C.L.C. Wilson and B.A. Southgate), fish (J. Lom), including lists of 149 alleged species of Trypanosoma and 33 of Trypanoplasma, and rodents (G.A.T. Targett and $\mathrm{P}$. Viens), with emphasis on recent immunological work (much of it their own). Two general chapters include one on nutrition (S.H. Hutner, C.J. Bacchi and $\mathrm{H}$. Baker) and one on characterisation, nomenclature and maintenance (W.H.R. Lumsden and D. Ketteridge).

Inevitably, perhaps, the choice of topics and their arrangement seems somewhat random; some deal with well known groups, presenting new information and syntheses, while others deal with parasites less often reviewed. Both groups are valuable, all contributions being authoritative, concise, comprehensive and comprehensible. Standards of editing and production are high - as, alas, is the price. There is a good general index (though the alphabetisation under the massive subheading "Trypanosoma" takes some getting used to), but no author index. Altogether, a volume to be recommended and either bought or coveted by all teachers or researchers of the kinetoplastids: it is sad that further volumes are not planned "at present".

J.R. Baker is at the MRC Biochemical Parasitology Unit, Molteno Institute, Cambridge, UK. 